\title{
Development of Energy Storage Rubber
}

\author{
Shinsuke OHKI, ${ }^{\mathrm{a}}$ Daisuke Hoshino, ${ }^{\mathrm{a}}$ Kenta Tate, ${ }^{\mathrm{a}}$ Kazuhiro Tachibana, ${ }^{\mathrm{b}}$ * \\ Michio Sugawara, ${ }^{\mathrm{b}}$ Tatsuo Nishina, ${ }^{\mathrm{a}}$ and Tsuyoshi Watanabe ${ }^{\mathrm{c}}$
}

\author{
${ }^{a}$ Graduate Program of Human Sensing and Functional Sensor Engineering, Graduate School of Science and \\ Engineering Yamagata University (4-3-16 Jonan, Yonezawa, Yamagata 992-8510, Japan) \\ ${ }^{\mathrm{b}}$ Department of Chemistry and Chemical Engineering, Faculty of Engineering, Yamagata University (4-3-16 Jonan, \\ Yonezawa, Yamagata 992-8510, Japan) \\ ${ }^{\mathrm{c}}$ Fukoku Co., Ltd. (6 Showa, Chiyodamachi, Ouragun, Gunma 370-0723, Japan)
}

Received January 31, 2007 ; Accepted May 2, 2007

\begin{abstract}
A new concept was proposed as the energy storage rubber to develop the batteries involving electrode materials in rubber matrix. The cathode active material $\left(\mathrm{LiMn}_{2} \mathrm{O}_{4}\right)$ and conductive carbon were mixed with rubber material to give flexible electrode. Some rubber materials were tested for this purpose, and the acrylic rubber matrix cathode gave the good charge/discharge cycle. The initial discharge capacity was $123 \mathrm{mAh} / \mathrm{g}$, which value corresponded to that obtained in electrolyte solution.
\end{abstract}

Key Words : Energy Storage Rubber, Lithium Ion Battery, Rubber Cathode

\section{Introduction}

Many characteristics such as power, electrical property, suitability in working environment, etc. are required for the production of batteries, which are designed so as to work well under this conditions. ${ }^{1)}$ The battery shape is also one of the important factors. The flexibility in the shape is required in some cases such as the electronic papers and organic EL displays. ${ }^{2)}$

It is necessary to use wide electrode surface in lithium ion battery, because the conductivity of organic electrolyte is lower than that of aqueous one. According, the Jelly roll type electrode is used by mixing and coating active material, conductive carbon and binder on metal sheet counter electrode., ${ }^{3,4)}$ It is, forever, difficult to give flexibility this type electrode.

On the other hand, the development studies are actively being carried out to apply the rubbers to new areas except for car industry. A few examples are in practice, however further studies are required for the development of higher-functional rubber.5) Since rubbers are one of polymer liquid, it is possible to dissolve or disperse many kinds of materials. For example, conductive and magnetic rubbers are in practical application by disperse metals, carbon, and magnetites.6)

The rubbers are usually prepared by molding and vulcanization including chemical reaction of mixture of law materials, and hence the resulting products are easily reformed to give flexibility and elasticity. ${ }^{7)}$ These characteristics can be differentiated from the plasticity of polymers. If the functions of energy storage are added to the rubbers, it is possible to realize the lithium ion batteries with the characteristics of rubbers. In this communication, we report the preparation and charge/discharge characteristics of cathode in a series of studies on the development of energy storage rubber.

\section{Experimental}

\section{1 Rubber materials and swelling test}

The following 12 kinds of rubbers were used as raw materials; silicone rubber (Q), butyl rubber (IIR), butadiene rubber (BR), isoprene rubber (IR), styrene-butadiene rubber (SBR), ethylene propylene rubber (EPDM), chloroprene rubber (CR), fluorocarbon-rubber (FKM), acrylic rubber (ACM), nitrile rubber (NBR), epichlorohydorin rubber (ECO), and hydrogenated nitrile rubber $(\mathrm{H}-$ NBR).

The mixture of raw rubber, vulcanizing agent and vulcanizing accelerator was mixed by roll, and then vulcanized at $170{ }^{\circ} \mathrm{C}$ for 10 minutes under hot press to give the sheet of $2 \mathrm{~mm}$ thickness. The test piece was cut out from this rubber sheet and soaked in propylene carbonate (PC), dimethoxyethane (DME), and PC+DME (50:50 by volume \%) at $40{ }^{\circ} \mathrm{C}$ for $72 \mathrm{~h}$ for swelling test. The change in the volume $(\Delta \mathrm{V} \%)$ before and after the soaking was evaluated as the degree of swelling.8)

\section{2 Preparation of test electrode}

Acrylic rubber (ACM) and EPDM were selected as the rubbers from the result of swelling test. The mixture of rubber, $\mathrm{LiMn}_{2} \mathrm{O}_{4}$ and graphite (or carbon black) was mixed by open roller, and then vulcanized at $170^{\circ} \mathrm{C}$ by hot press on $\mathrm{Al}$ foil. The resulting electrode was subjected to secondary vulcanization in air oven at $150{ }^{\circ} \mathrm{C}$ for $1 \mathrm{~h}$. The ratio of rubber, $\mathrm{LiMn}_{2} \mathrm{O}_{4}$ and conductive carbon was 100 , 40 , and 75 by weight for chronopotentiometry, and 100 , 30 , and 75 for cyclic voltammetry, respectively. This electrode was prepared at Fukoku Co. Ltd., and subjected to the measurements. Since the aluminum current collector was used, the flexibility was sacrificed because the measurements were carried out to confirm the charge and discharge characteristics.

\subsection{Electrochemical measurement}

The chronopotentiometry and cyclic voltammetry 
were carried out for the electrode (surface area: $1.5 \mathrm{~cm}^{2}$ ) prepared as shown in 2.2. Counter and reference electrodes were $\mathrm{Li}$, and the electrolyte was $1 \mathrm{~mol} \mathrm{dm}^{-3}$ $\mathrm{LiBF}_{4} / \mathrm{PC}+\mathrm{DME}$ ( $50: 50$ by volume $\%$ ) with water content below $50 \mathrm{ppm}$ in chronopotentiometry. The measurements were carried out in glove box of Ar gas atmosphere at room temperature. The applied current and cut-off potential were $0.1 \mathrm{~mA}$ and $3.0-4.4 \mathrm{~V}$ vs. $\mathrm{Li}^{+} / \mathrm{Li}$, respectively. The cyclic voltammograms were recorded at $0.1-0.01 \mathrm{mV} / \mathrm{s}$ between $3.4-4.4 \mathrm{~V}$ vs. $\mathrm{Li}^{+} / \mathrm{Li}$.

\section{Results and Discussion}

\section{1 Selection of rubber}

Table 1 show the results of swelling test in $\mathrm{PC}+$ DME. It is considered that the degree of swelling $(\Delta \mathrm{V} \%)$ is $\mathrm{PC}+\mathrm{DME}$ was classified into two groups of $\Delta \mathrm{V}>$ $100 \%$ and $\Delta \mathrm{V}<100 \%$. Therefore EPDM and ACM were selected as the rubber matrix for electrodes with lower and higher $\Delta \mathrm{V}$ values, respectively. Table 2 shows the solubility parameter (SP) of organic solvents and rubbers. It is known that the rubber swells well in the solvent with similar SP value. There is no data of SP for DME in text. The SP value of DME may be estimated to be about 9 , became the tested rubbers swell in this solvent. The SP value of $\mathrm{PC}$ was higher than that of rubbers. In PC + DME solution, that the characteristics of

Table 1 The swelling ratio $\mathrm{PC}+\mathrm{DME}$ (50:50).

\begin{tabular}{cc}
\hline$\Delta \mathrm{V} / \%$ & Polymer \\
\hline$<100$ & Q, IIR, IR, BR, SBR, EPDM, CR \\
$100<$ & ECO, FKM, ACM, NBR, H-NBR \\
\hline
\end{tabular}

Table 2 Solubility parameter of rubber and organic solvent.
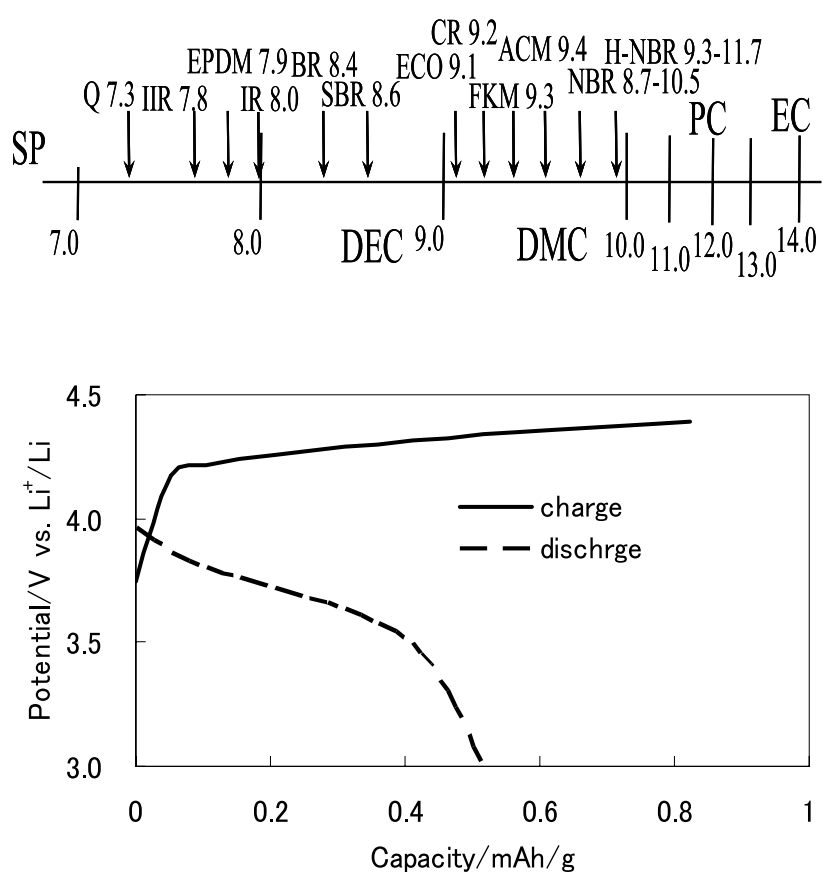

Fig. 1 Charge and discharge curves of the electrode with EPDM matrix.
PC become a dominant factor.

\section{2 Charge and discharge characteristics of cathode}

Figures 1 and 2 show the charge and discharge curves of the electrodes with EPDM and ACM. The rest potential of the electrode with ACM and EPDM matrixes was about 3.25 V. As shown in Fig. 1, when the EPDM with lower $\Delta \mathrm{V}$ value was used as a rubber matrix, the electrode resulted in the poor charge and discharge characteristics.

On the other hand, the potential of the electrode with ACM gradually increased in the charge process at 0.1 $\mathrm{mA}$. The charge capacity up to $4.4 \mathrm{~V}$ was $142 \mathrm{mAh} / \mathrm{g}$, and corresponded to the theoretical value. In the discharge process, the potential decreased gradually from $4.4 \mathrm{~V}$ to $3.8 \mathrm{~V}$, and then dropped rapidly to $3.0 \mathrm{~V}$. The discharge capacity from 4.4 to $3.0 \mathrm{~V}$ was $123 \mathrm{mAh} / \mathrm{g}$ and the efficiency of charge and discharge was $87 \%$. This value corresponded to that obtained in electrolyte solution.

The content of active material $\left(\mathrm{LiMn}_{2} \mathrm{O}_{4}\right)$ and carbon were about 20 and $40 \%$, respectively. This experiment was carried out to confirm the feasibility of charge/discharge in the rubber matrix. It is required to increase the content of active material, and to apply to the battery assembly with negative electrode. Further studies are now in progress.

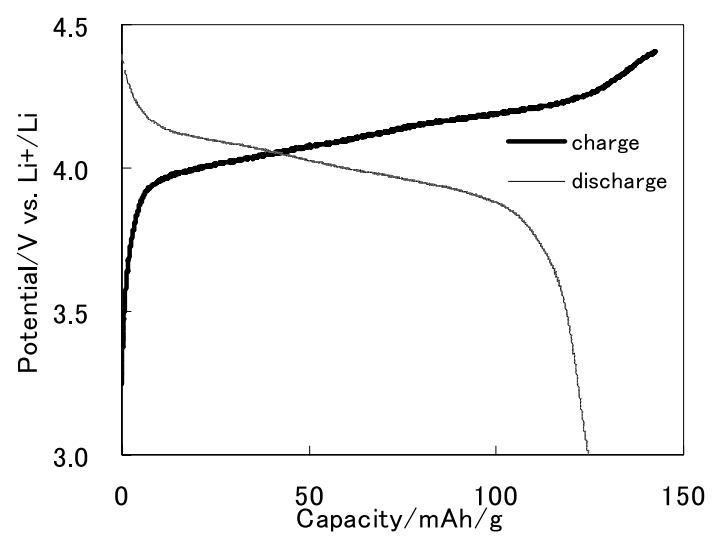

Fig. 2 Charge and discharge curves of the electrode with ACM matrix.

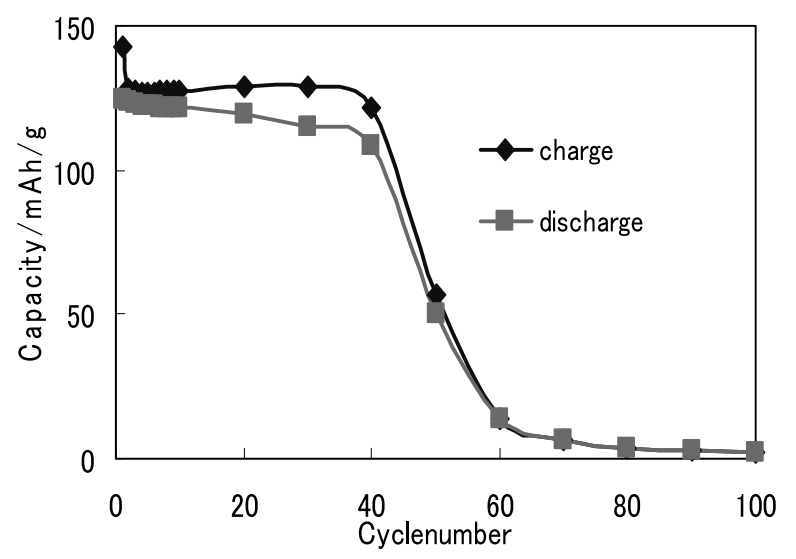

Fig. 3 Cycle performance of ACM matrix electrode. 
Figure 3 shows the cycle performance of ACM matrix electrode. The capacity decreased slowly, and decreased rapidly after 50th cycle. After the charge/discharge cycle test, the electrode taken out from the cell was observed to be loose contact between the rubber and aluminum foil. The good charge/discharge may be expected by improving the loose contact.

\section{3 Evaluation by cyclic voltammetory}

Figure 4 shows the cyclic voltammograms of ACM matrix electrode at various scan rates. A characteristic two step-reaction process was observed from 0.01-0.05 $\mathrm{mV} / \mathrm{s}$. The increase in scan rate resulted in the large

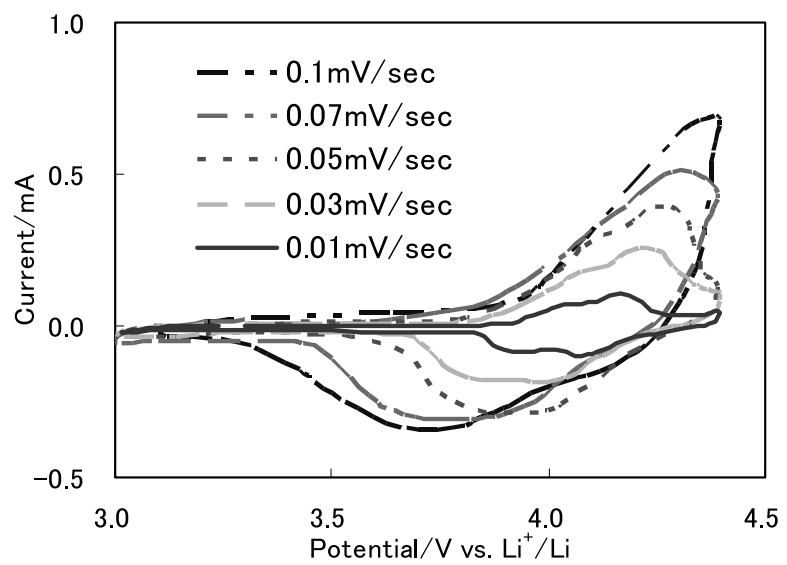

Fig. 4 Cyclic voltammograms curve of ACM matrix electrode. potential shift by IR drop. In the voltammogram from $3.8-4.4 \mathrm{~V}$ at $0.05 \mathrm{mV} / \mathrm{s}, \mathrm{C}$ rate evaluated by the scan rate and current was $0.3 \mathrm{C}$.

\section{Conclusion}

The cathode of lithium ion batteries was prepared by mixing rubber, conductive carbon and $\mathrm{LiMn}_{2} \mathrm{O}_{4}$ as active materials, and the charge and discharge properties were investigated. The obtained results are as follows.

1. This electrode worked as the cathode of lithium ion batteries, and the capacity corresponded to that in electrolyte solution.

2. It was preferable to select the rubber with higher swelling property in the electrolyte.

\section{References}

1) D. Linben, Battery Handbook, Asakura Shoten, p. 31 (1996) (translated in Japanese by T. Takamura).

2) Japanese Patent Kokai, 2005-332591 (2005).

3) Z. Takehara, High Density Lithium Secondary Batteries, Technosystem, p. 217 (1998) [in Japanese].

4) A. Yoshino, Denchi Binran (Eds. Y. Matsuda and Z. Takehara), Maruzen, p.281 (2001) [in Japanese].

5) T. Watanabe and K. Komatsu, Yasashii Gomu Erastmer, Sankyo Shuppan, p. 60 (1997) [in Japanese].

6) T. Watanabe, H. Takahashi, T. Matsushita, M. Endo, K. Tachibana, T. Nishina, and S. Ohki, The 46th Battery Symposium in Japan, Abstr., 3D13 (2005) (in Japanese).

7) S. Yamashita and K. Komatsu, Erastmer, Kyoritu Syuppan, p. 9 (1994) [in Japanese].

8) JIS, K6258 (2003). 